This item was submitted to Loughborough's Research Repository by the author.

Items in Figshare are protected by copyright, with all rights reserved, unless otherwise indicated.

\title{
Turbo-discharging: predicted improvements in engine fuel economy and performance
}

PLEASE CITE THE PUBLISHED VERSION

http://dx.doi.org/10.4271/2011-01-0371

PUBLISHER

(C) SAE International

VERSION

VoR (Version of Record)

LICENCE

CC BY-NC-ND 4.0

\section{REPOSITORY RECORD}

Williams, Andrew M., Alan T. Baker, and Colin P. Garner. 2019. "Turbo-discharging: Predicted Improvements in Engine Fuel Economy and Performance". figshare. https://hdl.handle.net/2134/8710. 
This item was submitted to Loughborough's Institutional Repository (https://dspace.lboro.ac.uk/) by the author and is made available under the following Creative Commons Licence conditions.

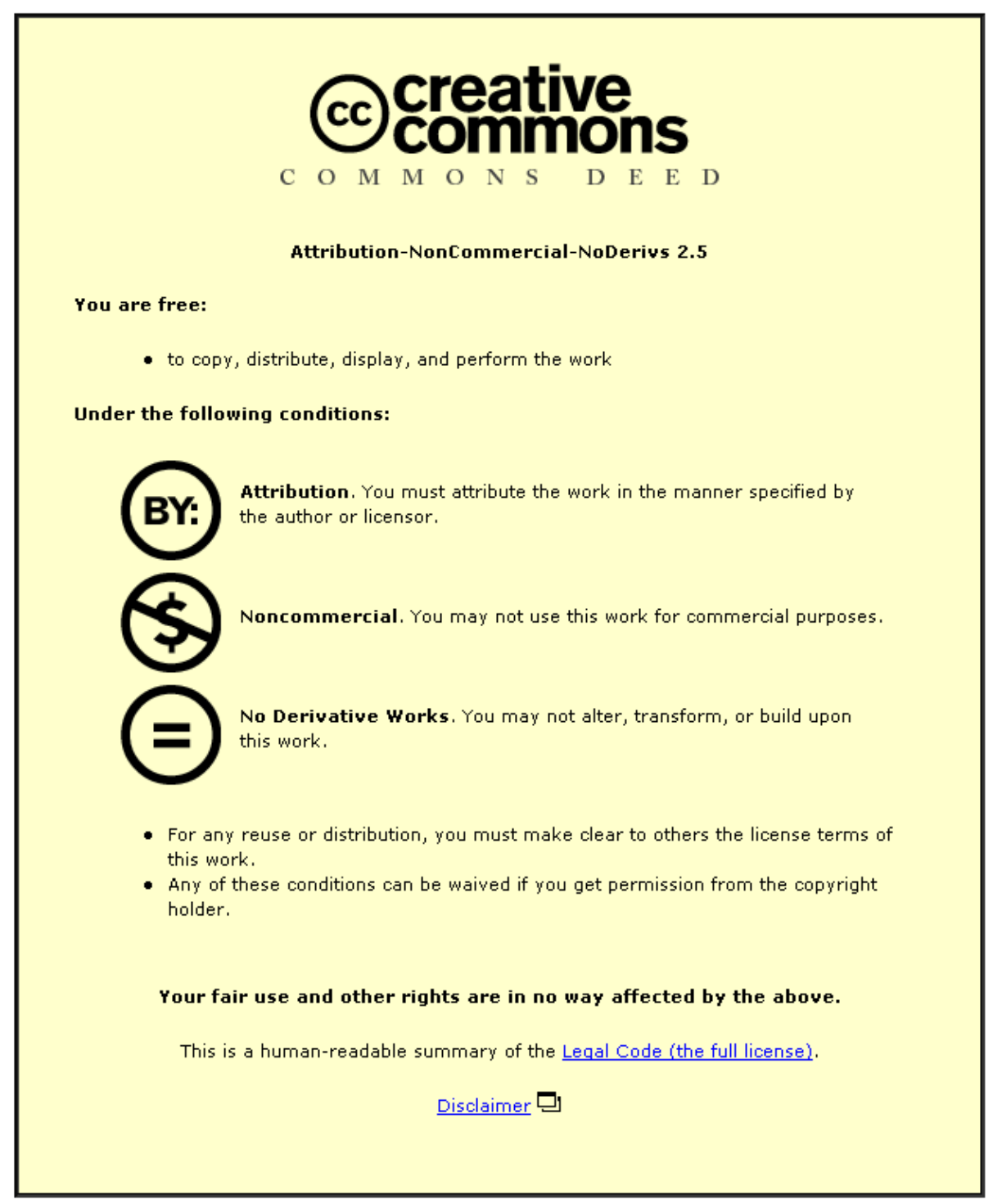

For the full text of this licence, please go to: http://creativecommons.org/licenses/by-nc-nd/2.5/ 


\title{
Turbo-Discharging: Predicted Improvements in Engine Fuel Economy and Performance
}

\author{
Andrew M Williams, Alan T Baker and Colin P Garner \\ Loughborough Univ.
}

\begin{abstract}
The importance of new technologies to improve the performance and fuel economy of internal combustion engines is now widely recognized and is essential to achieve $\mathrm{CO}_{2}$ emissions targets and energy security. Increased hybridisation, combustion improvements, friction reduction and ancillary developments are all playing an important part in achieving these goals. Turbocharging technology is established in the diesel engine field and will become more prominent as gasoline engine downsizing is more widely introduced to achieve significant fuel economy improvements.
\end{abstract}

The work presented here introduces, for the first time, a new technology that applies conventional turbomachinery hardware to depressurize the exhaust system of almost any internal combustion engine by novel routing of the exhaust gases. The exhaust stroke of the piston is exposed to this low pressure leading to reduced or even reversed pumping losses, offering $>5 \%$ increased engine torque and up to $5 \%$ reduced fuel consumption. This method has the distinct advantage of providing performance and fuel economy improvements without significant changes to the structure of the engine, the combustion system or lubrication system.

The Turbo-Discharging concept is introduced and analyzed. A combination of filling/emptying models and 1-D gas dynamic simulations were used to quantify the energy flows and identify optimum valve timings and turbomachine characteristics. 1-D gas dynamic simulation was then used to predict primary fuel economy benefits from TurboDischarging. Secondary benefits, such as extended knock limits are then discussed.

\section{INTRODUCTION}

Engine fuel consumption has been the focus of significant research effort for a number of years and is encouraging the introduction of, for example, downsized engines e.g[1] $^{\text {, }}$ throttleless air systems $[\underline{2}]$, new combustion systems as well as new prime movers. The need to reduce fuel consumption is driven by concerns over environmental sustainability and energy security. Despite developments in fuel cell and electric vehicle technologies, it is now widely recognized that a large fraction of future vehicles will rely on internal combustion (IC) engines and, therefore, it is important to make maximum use of the fuel energy to minimize IC engine fuel consumption. In particular, new technologies that do not require significant redesign, development and calibration of established engine sub-systems while delivering significant fuel economy benefits are highly valuable.

To improve the thermal efficiency of IC engines, engineers can address the most significant parasitic losses of the fuel energy. The most commonly quoted are the energy rejected through the coolant and exhaust systems, which has spurred large efforts to recover this thermal energy. Thermo-electric heat recovery systems typically convert $<5 \%$ of the thermal energy flowing through them and require rejection of the heat at lower temperatures fundamentally requiring larger heat exchangers $[3]$. Closed cycles (e.g. Rankine cycle[4]) are applied to exhaust systems in a research context achieving up to $20 \%$ improvements in fuel economy, although they typically require bulky and heavy hardware. Indeed, packaging and heat rejection requirements are significantly increased with exhaust heat recovery methods as most of the energy must be lost through heat exchangers rather than exhausted with the combusted gases. This makes them less attractive for engine manufacturers. Reduction of parasitic power losses can offer significant improvements. For 
example, electrical actuation $[\underline{5}]$ offers the engineer the ability to use ancillaries only when they are needed and in many cases reduce the fuel consumption across much of the engine range. Friction also receives a lot of attention and great improvements are being made by, for example, surface treatments and material developments $[\underline{6}]$.

Considering the combustion cycle, significant losses are caused during engine breathing, particularly in throttled engines where the reduction in pumping work has resulted in some of the most significant fuel economy improvements to date, i.e. engine downsizing. However, there is still a significant amount of energy remaining in the gas at the end of the expansion stroke as the cylinder volume at this time is often geometrically limited to that of the compression stroke. If the gas could be expanded to that of the exhaust sink pressure, fuel economy can be dramatically improved. The turbine in conventional turbocharger arrangements does recover some of this energy and uses it to compress the intake air system, however, much of the energy is lost, especially at higher speeds with a wastegate enabled turbocharger.

Möller et $a\left[{ }^{[7]}\right.$ have implemented turbocharging using only the energy contained within the blowdown event which has the advantage of reducing the pumping work as the piston nolonger pushes the exhaust gases through the turbine. This method utilized a divided exhaust period first described in $[\underline{8}]$. This demonstrated significant torque improvements at mid and high engine speeds due to pumping work and reductions in low speed torque due to reduced turbine mass flow. Such an approach to isolating the blowdown energy from the main exhaust flow offers an energy source that could be used in more ways than simply turbocharging.

This paper presents for the first time the Turbo-Discharging system which recovers the blowdown energy and uniquely applies this energy to depressurize the exhaust system. By exposing the piston to this low pressure during the exhaust stroke, the pumping work can be reduced or even reversed resulting in positive power out of the engine during the gas exchange. Secondary benefits such as reduced residual content may extend existing knock limits to give further advantages.

\section{TURBO-DISCHARGING}

To recover the blowdown energy without demanding the piston to push the exhaust gases through the turbine there needs to be multiple parallel exhaust flow paths. This is achieved by connecting one exhaust valve to a high pressure manifold (i.e. connected to the turbine inlet) and the second to a low pressure manifold (i.e. by-passing the turbine), shown in Figure 1. This allows the blowdown energy to be recovered by the turbine while the piston speed is small, resulting in very small work done by the crankshaft exhausting the gas. During the exhaust stroke of the piston, the low pressure valve is open and the low pressure within the cylinder acts to reduce the pumping losses when compared to pushing the air through the turbine. It is clear that a rapid valve opening is desirable and in many cases will be limited by the valve gear. Careful consideration was also given to the overlap of the valves between the high and low pressure manifolds as this could generate recirculating flows, dissipating useful energy.

The energy can be used in a number of ways including turbocompounding and turbocharging $[\underline{5}]$. In the case of TurboDischarging the energy is used to depressurize the exhaust gases by way of a compressor downstream in the exhaust system. Such an arrangement is shown for a naturally aspirated (NA) or supercharged engine in Figure 1. By reducing the pressure downstream of the turbine (i.e. increasing the pressure ratio) there is the added advantage that more energy can be extracted from the exhaust blowdown flow. Removing heat from the exhaust gas before the compressor increases the gas density and increases the pressure ratio across the compressor for the same power input. Since it is the pressure that gives an advantage through the crankshaft, the option of installing a heat exchanger to maximize this heat loss should be considered. With potential technologies such as exhaust thermal energy recovery, it is likely that in the future there will be a mechanism for removing exhaust thermal energy and, therefore, reduced incentive for an additional heat exchanger.

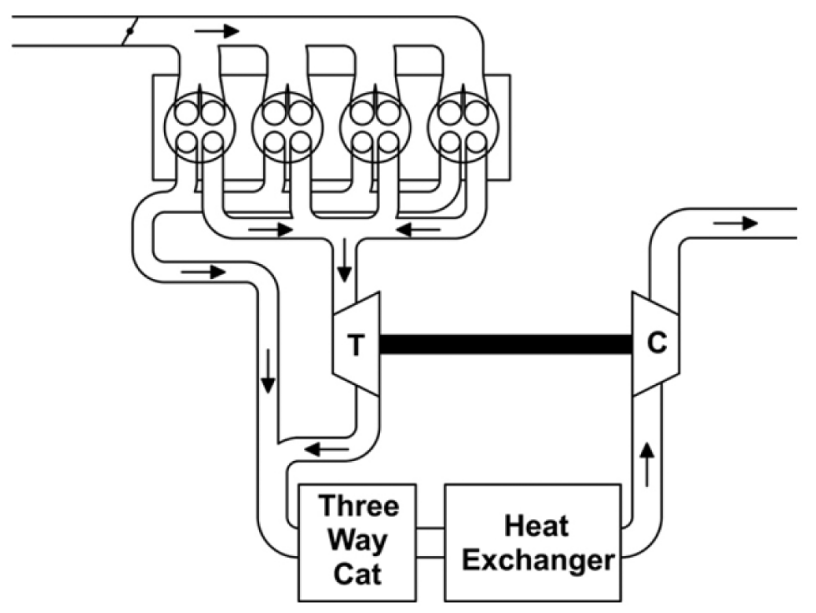

Figure 1. Schematic of an example exhaust arrangement of a Turbo-Discharged naturally aspirated engine

To implement Turbo-Discharging on a turbocharged (TC) engine the blowdown energy can be recovered in the same way with the turbocharger turbine situated after the two exhaust manifolds recombine, shown in Figure 2. This ensures the turbocharger receives the full engine flow to help maintain low speed torque and transient response. Since the low pressure side of the TC turbine can be $\ll 0.5$ bar 
absolute, the pressure ratio across the turbine is significantly higher and either more turbine power can be taken for the same engine back pressure, or the same power can be transferred to the compressor for a lower engine back pressure. The net result is a lower exhaust manifold pressure than without the Turbo-Discharging system leading to the same advantages previously described for the NA engine.

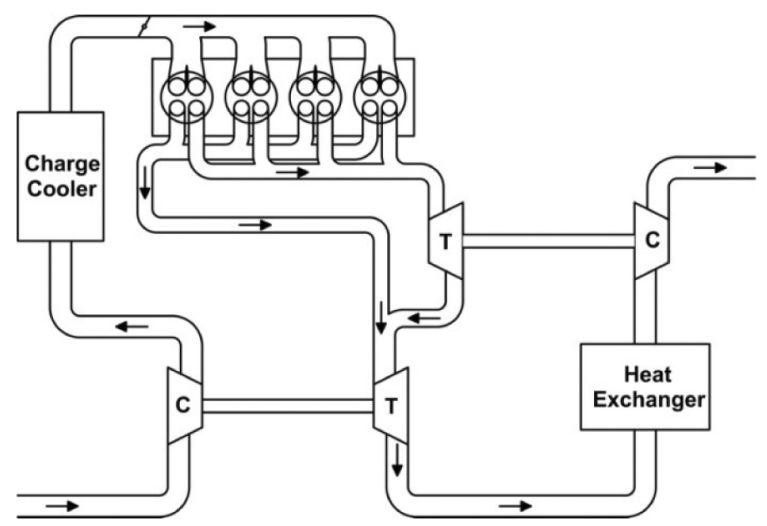

Figure 2. Schematic of an example exhaust arrangement of a Turbo-Discharged turbocharged engine

The work presented in this paper focuses on the modeling studies that have been undertaken to explore the benefits that may be achievable with this technology for NA engines and $\mathrm{TC}$ engines. The knowledge generated from these studies will also apply to supercharged engines and different combustion systems. The comparison of conventional engine performance with Turbo-Discharged engine performance can be done with either comparable displacement or comparable engine power. The former will demonstrate lower fuel economy benefit and increase engine torque and power. The latter will demonstrate improved fuel economy with some performance improvement. Where appropriate this paper presents both approaches.

In summary, Turbo-Discharging is a new and novel approach to using normally wasted energy to reduce pumping work and improve scavenging by reducing the exhaust system pressure during the exhaust process. It can be applied to NA engines and pressure boosted engines regardless of combustion system or engine topology. The modeling presented here for NA engines was considered a logical starting point to build sufficient knowledge to successfully apply TurboDischarging to TC and downsized engines. A discussion of the potential performance with turbocharged engines is therefore also presented.

\section{TURBO-DISCHARGING NATURALLY ASPIRATED ENGINES}

To predict the potential fuel economy benefits of TurboDischarging, two stages of modeling have been undertaken.
Firstly, a series of thermodynamic cycle simulations have been used to investigate the availability of energy and its potential impact on the exhaust system pressure and engine fuel economy. Secondly, one dimensional gas dynamics simulations were undertaken to more realistically quantify the system performance, in particular flow losses through valves. Additionally, the 1-D gas dynamics simulations indicate how sensitive the system is to different variables and to aid the design of preliminary hardware for future engine test-bed studies.

\section{THERMODYNAMIC CYCLE SIMULATIONS}

\section{Method}

To calculate crankshaft work and fuel consumption, a 4stroke cycle, shown in Figure 3 was simulated with the following stages:

\section{Constant pressure induction stroke}

2. Compression of an ideal gas with heat transfer using finite time methods

\section{Constant volume complete combustion}

4. Expansion of an ideal gas with heat transfer using finite time methods

5. Blowdown event (linked to turbine calculations)

6. Constant pressure exhaust stroke.

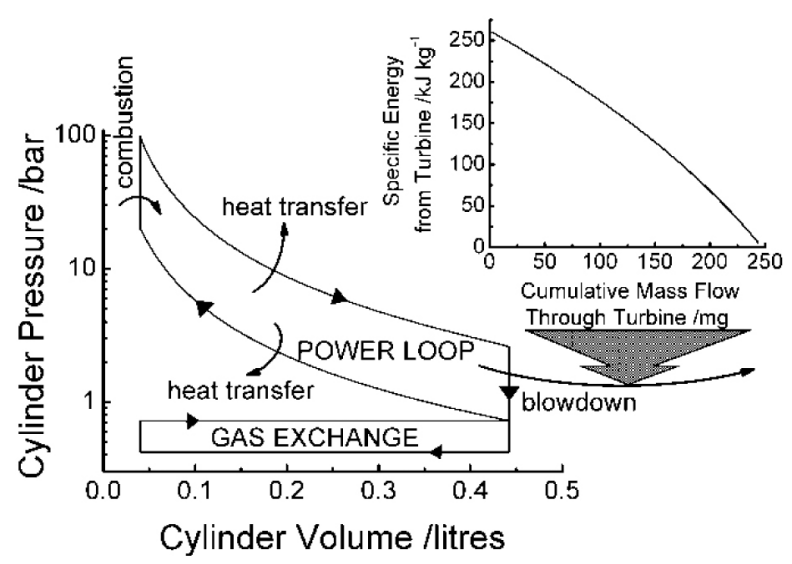

Figure 3. Pressure-volume diagram representing the 0-D cycle model

The blowdown event was considered the only contributor to the Turbo-Discharging energy turbine flow. During blowdown, the cylinder was considered a fixed volume with initial pressure and temperature. The blowdown event was discretised. For each discretisation, a small amount of gas expanded through the turbine from the cylinder pressure and temperature to the pressure in the low pressure exhaust 
manifold. This causes a lower in-cylinder pressure and lower in cylinder temperature which became the input parameters for the subsequent discretised step until the cylinder has reached the pressure in the low pressure exhaust manifold. This represents a zero volume manifold with no valve flow restriction and an instantaneous blow-down event with no inertial considerations.

The energy extracted by the turbine is then used to compress the exhaust flow in the low pressure manifold back to ambient pressures. The low pressure manifold is considered to be infinite in size and the inertia of the turbomachine such that it operates at constant speed. This results in a constant low pressure in the exhaust system. The low pressure is iterated to satisfy the first law of thermodynamics. In the example shown in Figure 3, the energy extracted from the turbine is enough to reduce the exhaust pressure below the intake system pressure resulting in positive work out during the breathing cycle.

\section{Results and Discussion}

The energy available to the Turbo-Discharging system is a strong function of pressure at the start of the blowdown event as this affects the fraction of the cylinder contents that pass through the turbine. The effect of temperature at the end of expansion is only significant when the exhaust gases are being cooled as the additional work recovered from the turbine is counteracted by the additional work required by the compressor to achieve the same pressure ratio. This is clearly demonstrated in the predicted exhaust system pressures shown in Figure 4. However, if the gas is exhausted from the cylinder at high temperatures and then cooled, the compressor can generate even higher pressure ratios as the corrected compressor flow is reduced. Figure 4 shows that with cooling the effect of temperature at the end of expansion is as significant as the effect of pressure at the end of expansion. Highlighted on the plot are typical regions within which the simulation predicts the NA stiochiometric engines (e.g. conventional gasoline engines) and NA lean burn engines (e.g. diesel engines) to operate. The turbocharged engines are not shown on this plot as the pressure ratio across the boost system turbine would add another dimension. However, the importance of pressure and temperature at the start of the blowdown event will still be significant.

This data suggests that with an ideal turbomachine, exhaust pressures could be brought as low as 0.5 bar (absolute) without any cooling. With cooling, this figure could reach as low as 0.1 bar (absolute). Clearly the turbomachine efficiency will have a significant effect on this, which is considered in the 1-D gas dynamics simulations.

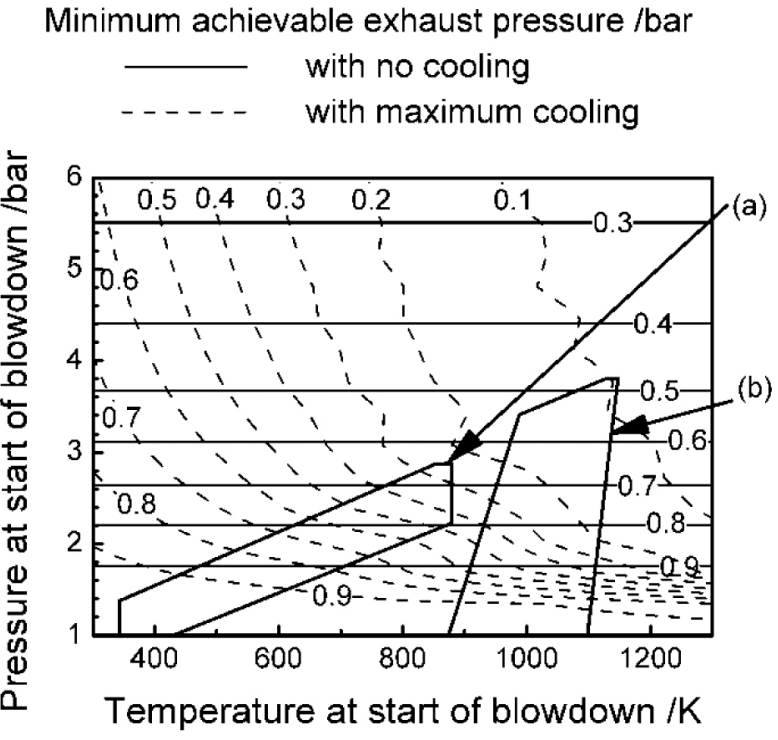

Figure 4. Effect of pressure and temperature at start of blowdown on achievable exhaust manifold pressure. Typical operating regions are shown for (a) a NA lean burn engine and (b) a NA throttled engine

When the exhaust system pressure is reduced the pumping work is also reduced or, in some cases, reversed giving an additional power loop. Figure 5 shows the projected torque increase based on the thermodynamic cycle calculations. There is a clear benefit to engine torque both with and without the heat exchanger. However, the benefit is approximately double if the heat is removed with the heat exchanger. These predictions are expected to be an underestimate as they do not consider the trapped residual fraction. With lower exhaust pressures the residual fraction will be reduced and more fresh charge will be able to be inducted into the cylinder. At higher loads the benefit is slightly increased due to the higher temperatures at the start of the blowdown event. This increases the fraction of the cylinder contents that pass through the turbine and therefore the energy available to depressurize the exhaust system. This result is expected to be an overestimate at higher engine speeds due to pressure losses through pipework and specifically across the valves. 


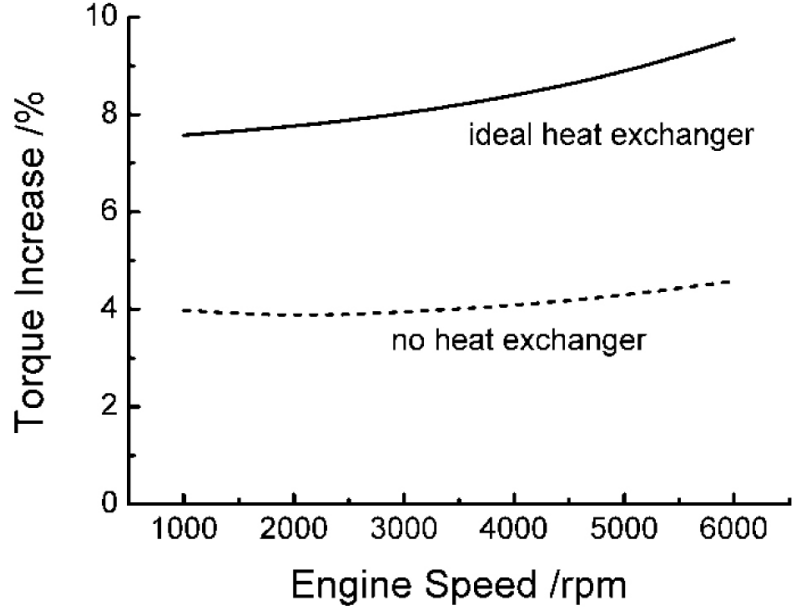

Figure 5. Effect of heat exchanger on the potential torque increase

Figure 6 shows the projected fuel economy benefit over the engine map for the NA throttled stiochiometric engine of comparable displacement. The fuel economy benefit is a function of the change in pumping mean effective pressure (PMEP) resulting from the use of Turbo-Discharging. As the energy used to depressurize the exhaust system is increased, the exhaust system pressure asymptotically approaches an absolute vacuum. At high loads, therefore, the relative benefit reduces. At mid loads the benefit is most significant. At lower loads, the throttling of the engine can be such that there is no longer a positive blowdown event (i.e. the pressure at end of expansion is lower than atmospheric pressure). Therefore at low speeds and loads, within the assumptions of the calculations, there was no energy recovered by the turbine and no benefit of the Turbo-Discharging system. Under these conditions the valves do not offer significant restriction to the exhaust flow and, therefore, the impact of the TurboDischarging system on the pumping work can be negligible. Without cooling, the benefit reduced to $\sim 3 \%$. Importantly, there is still potential for fuel economy improvements over a conventional engine due to the isolation of the high and low pressure manifolds. This indicated that a heat exchanger could be sized for optimum mid-low speed mid-low load operation and still achieve benefits at higher speeds and loads.

The unthrottled NA stiochiometric engine results, shown in Figure 7 are based on a variable early or late intake valve closing strategy for load control instead of the throttle. The results demonstrate similar trends. However, the threshold at which there is no longer a blowdown event is at a higher load due to the more efficient operation of the engine.

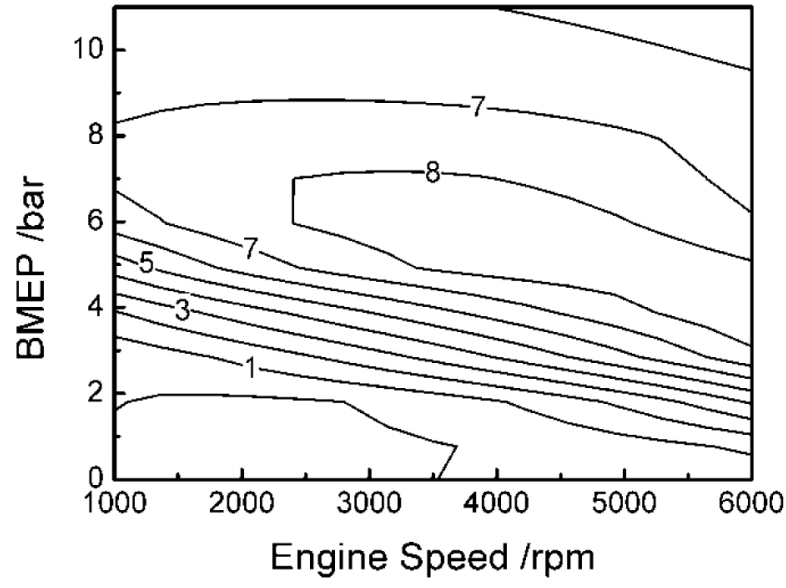

Figure 6. 0-D model predicted map of fuel economy benefit for a naturally aspirated throttled gasoline engine

(\%)

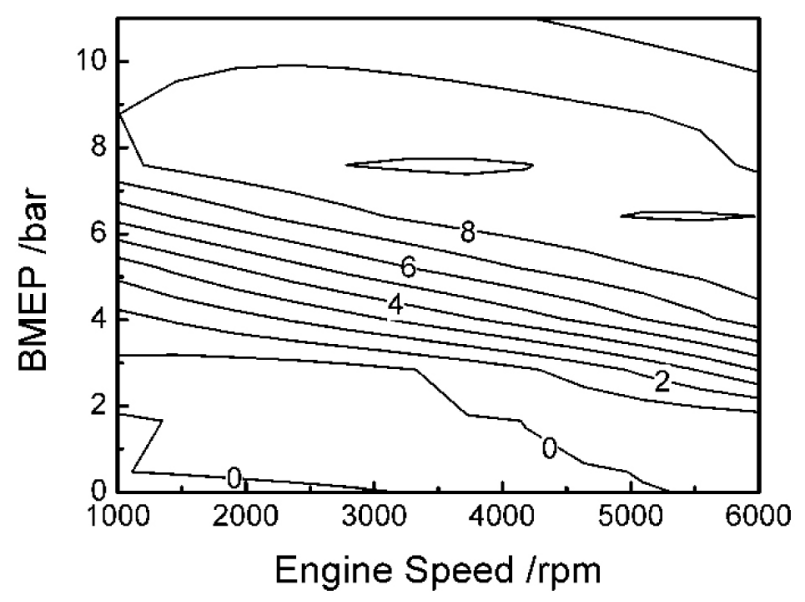

Figure 7. 0-D model predicted fuel economy benefit map for a naturally aspirated stoichiometric fuelled throttleless engine (\%)

The effect of turbomachine efficiency (including compressor, turbine and mechanical efficiency) on the exhaust system pressure is significant. This effect is shown for selected engine speed and load points in Figure 8. The optimization of the turbomachine for efficient operation is, therefore, important. Trade-offs that have been made for inertial reasons on turbochargers should be reconsidered for the case of the Turbo-Discharging system. 


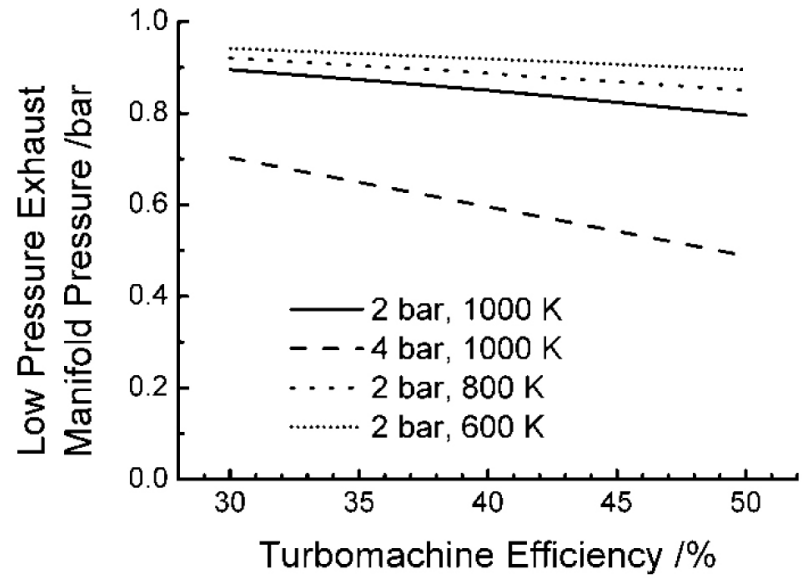

Figure 8. Effect of turbomachine efficiency on exhaust system pressure at different initial blowdown conditions

\section{ONE-DIMENSIONAL GAS DYNAMICS SIMULATIONS}

\section{Method}

A validated Ford Sigma 1.4 litre naturally aspirated engine model (using Ricardo WAVE) was used for this study of Turbo-Discharging. The exhaust ports were isolated to give a high (HP) and a low pressure (LP) manifold which were connected to the inlet and outlet of the turbine respectively. This is shown schematically in Figure 1. The specifications of this engine are shown in Table 1. The generic turbomachine used for the simulation was comparable in size to a small automotive turbocharger.

Table 1. Naturally aspirated simulated engine characteristics

\begin{tabular}{|l|l|}
\hline Bore & $76.0 \mathrm{~mm}$ \\
\hline Stroke & $76.5 \mathrm{~mm}$ \\
\hline Connecting rod length & $136.3 \mathrm{~mm}$ \\
\hline Number of cylinders & 4 \\
\hline $\begin{array}{l}\text { Number of valves } \\
\text { per cylinder }\end{array}$ & 4 \\
\hline Compression ratio & 10.3 \\
\hline Fuel & Gasoline \\
\hline
\end{tabular}

To ensure a valid comparison the combustion, heat transfer, exhaust sink pressure and intake valve timings were consistent between the models. There is, therefore, scope for further improvement with a recalibration of the intake valve timings. The exhaust valve timings were altered to allow recovery of the blow-down pulse independently of the main displacement pulse. The valve event was scaled within the geometric constraints of the valve gear and within a $110 \%$ limit of the existing valve acceleration. An example of the final valve events without the ramp are shown in Figure 9. The amount of overlap between the intake and exhaust valves is very small to reduce drawing fresh charge through the cylinder into the exhaust manifold. With a port fuel injection engine this is more important than with direct injection strategies where the injection timing can be used to prevent unburnt fuel entering the exhaust. At high loads, drawing fresh charge into the exhaust system may have advantages for thermal limits on the turbomachine and scavenging. For all cases presented in this section, fixed valve timings have been used. Availability of variable valve actuation (VVA) systems on future engines is expected to improve the fuel economy improvements noticeably.

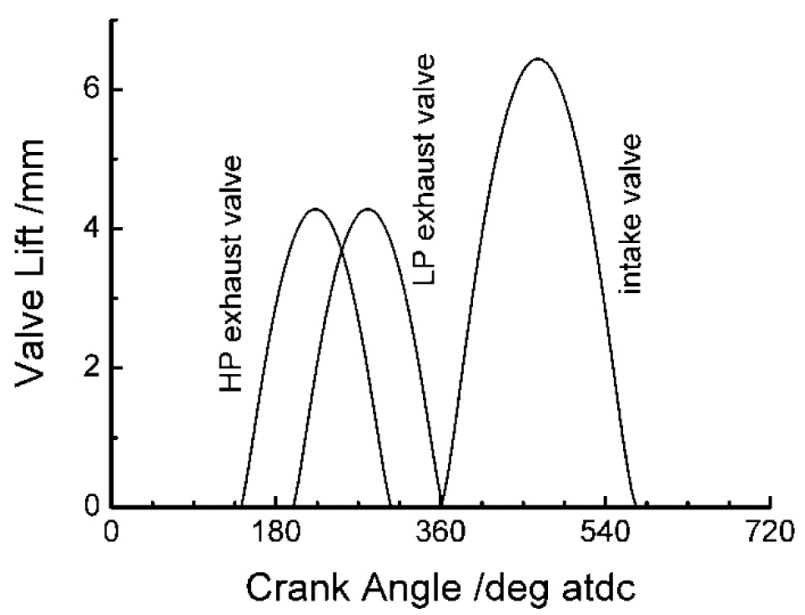

Figure 9. Example Turbo-Discharging valve events (without ramp) used for 1-D simulations

\section{$\underline{\text { Results and Discussion }}$}

Figure 10 shows the effect of Turbo-Discharging on the engine torque and fuel consumption at wide open throttle. The increase in engine torque was significant and varies from approximately $7 \%$ to $16 \%$ across the speed range. The associated increase in peak power was $\sim 10 \%$. At the same time, the specific fuel consumption of the engine at peak torque was reduced. This was anticipated due to the relative reduction in friction work and positive benefit associated with the reduced exhaust back pressure. However, the fuel consumption also increased. The effect of the low exhaust pressure on engine breathing, in-cylinder residuals and the amount of fresh charge that was inducted to the cylinder was as significant as the increased power resulting from reduced pumping work. The torque curve increase over the entire engine speed range is a very positive result. It indicates that for typical power densities of NA engines, the breathing 
advantages resulting from a low pressure manifold overcome the detriment resulting from reduced valve lift and opening durations. Later in this paper the effect of increasing engine power density is discussed.

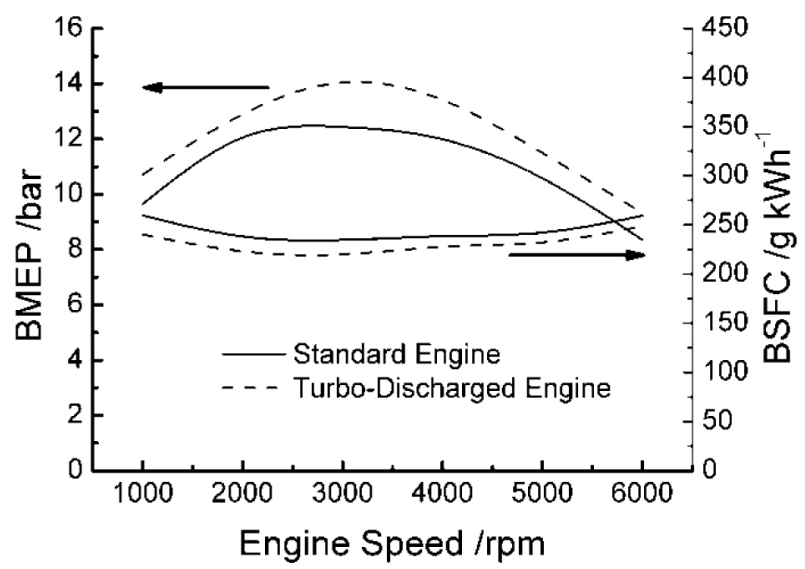

Figure 10. Comparison of torque curve between conventional and Turbo-Discharged $\mathrm{NA}$ engines

As the engine load is reduced, the energy available in the blowdown pulse reduces and the achievable exhaust system pressure also reduces. Figure 11 shows a map of the average exhaust port pressure as a function of engine speed and load. These are absolute pressures and are therefore typically lower than the exhaust sink pressure of 1.05 bar. At peak torque, the exhaust system pressure was seen to reduce to below 0.5 bar. If the piston is exposed to this pressure over its entire exhaust stroke, $\sim 0.5$ bar increase in BMEP over the baseline could be expected. The 2 bar increase $(\sim 16 \%)$ observed is, therefore, attributed to secondary effects such as reduced residuals and improved breathing. As anticipated, the lower regions of the engine load do not show a significant reduction in exhaust system pressure. This is due to the reverse blowdown, where at exhaust valve opening, exhaust gases are drawn into the cylinder and cannot be recovered by the turbine arrangement described.

When comparing the translation of exhaust system pressure to fuel economy benefit, two cases were considered: comparable displacement and comparable engine power. Figure 12 shows a map of the predicted fuel economy improvement as a function of engine speed and load for the comparable displacement engines. There was a translation of the exhaust system pressure to reduced pumping work at most engine conditions, specifically in the lower half of the engine speed range. At higher speeds, the benefit was reduced, resulting from the flow restrictions through the valves. Only at very high speeds and loads were significant fuel economy detriments $(>1 \%)$ observed.

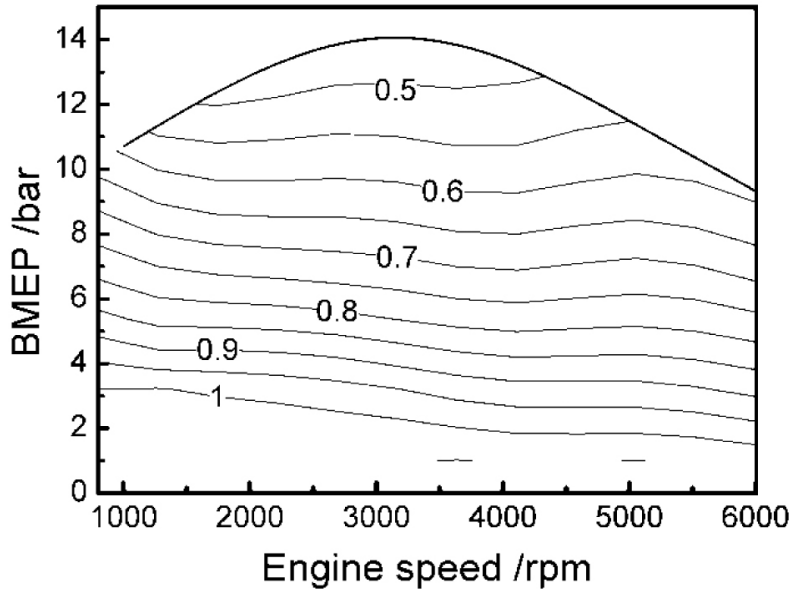

Figure 11. Exhaust port absolute pressure (in bar) as a function of engine speed and load

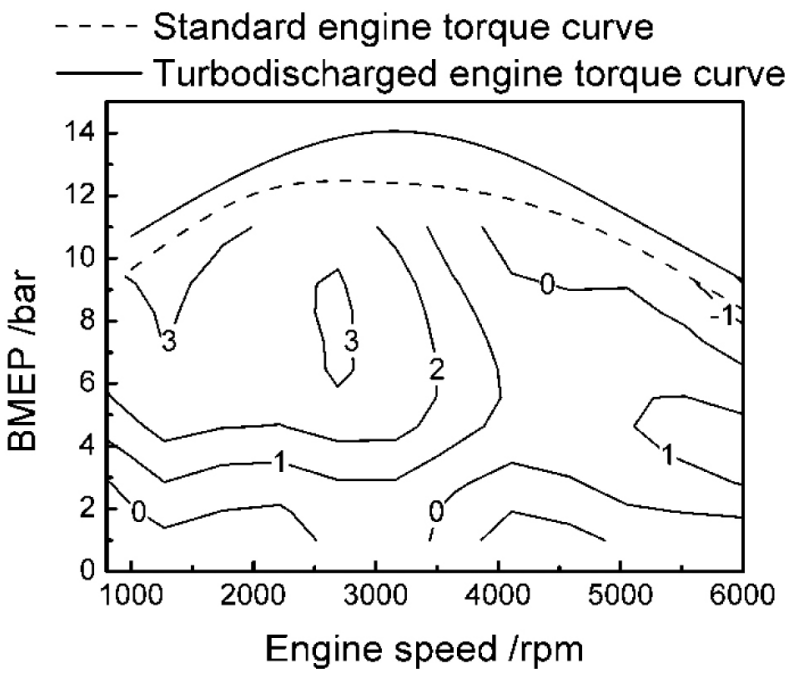

Figure 12. Fuel economy benefit for a comparable displacement engine

Considering the exhaust system pressure, it was possible to estimate the ideal fuel economy improvement based on the potential effect of exhaust pressure on PMEP and the reduction in residual content on throttling requirements. This considered the case when the low exhaust system pressure is applied to the cylinder throughout the entire exhaust stroke, and therefore gave a quantitative term that could be compared to the actual fuel economy benefit to evaluate how effectively the exhaust system pressure is translated into fuel economy improvement. It is calculated as

$$
I_{\text {expected }}=\frac{\left(P_{e x_{-} N}-P_{e x_{-} T}\right)}{P_{B M E P}}-\frac{P_{i n_{-} N}}{P_{B M E P}}\left(1-\left(1-\frac{P_{e x_{-} N}-P_{e x_{-} T}}{P_{B M E P}}\right)\left(\frac{1-r_{N}}{1-r_{T}}\right)\right)
$$


where $I_{\text {expected }}$ is the expected improvement to BSFC (\%), $P$ is pressure and $r$ is residual fraction. Subscript ex refers to exhaust port, in refers to intake port, $T$ to the TurboDischarged engine, $N$ to the baseline engine and $B M E P$ to the brake mean effective pressure. Equation 1 does take into account the additional throttling required to achieve the same load as the residual content and PMEP reduces. The effectiveness of the chosen valve profiles and timings to translate the exhaust system pressure into fuel economy improvement was therefore be defined as

$$
E_{\text {breathing }}=\frac{I_{\text {actual }}}{I_{\text {expected }}} \times 100
$$

where $I_{\text {actual }}$ is the actual fuel economy benefit and $E_{\text {breathing }}$ is the breathing effectiveness. It is worth highlighting that the effectiveness can potentially increase beyond 100 if the manifolds are successfully tuned. Figure 13 shows the calculated breathing effectiveness across most of the engine map. It can be seen that the valve profiles were successful at lower speeds and struggled to achieve a lower pressure differential across the valves at higher engine speeds. There is scope, therefore to reduce the amount of work being used to depressurize the exhaust at higher engine speeds to allow the increase of valve lift and duration.

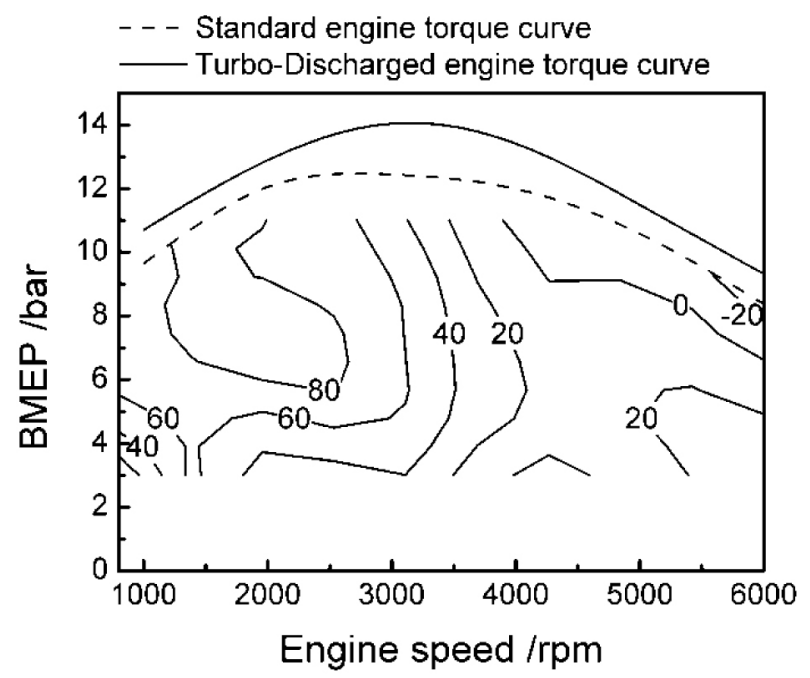

Figure 13. Map of breathing effectiveness, $E_{\text {breathing }}(\%$, defined in Eq 2)
When considering an engine of comparable power, the comparison became that shown in Figure 14. The torque curves are shown for comparison and are not significantly different. The highest fuel economy improvements are again around the low-mid speed and mid load portions of the engine map, reaching $>5 \%$ and, importantly, fuel economy improvements were recognized at all engine speeds and loads. Of particular importance are the fuel economy benefits achieved at very low loads due to reduced friction and pumping work. In practice, the engine designers would be able to work in a continuous spectrum between the cases presented in Figures 12 and $\underline{14}$, balancing the value of improved fuel economy with improved engine torque and power.

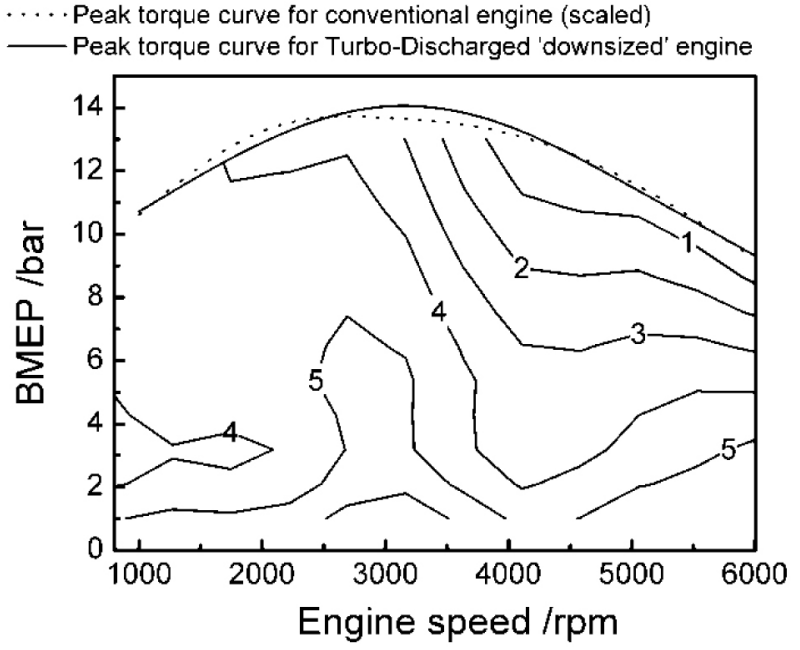

Figure 14. Fuel economy improvement (\%) for a comparable power engine

The change of residual fraction is of interest as it is the most significant effect of Turbo-Discharging on combustion. With reduced residual content the knock limit is expected to be further extended allowing potentially increased power density and potentially higher compression ratios than used in these simulations. Figure 15 shows that the residual content was significantly reduced across most of the engine range. At high loads, $50 \%$ reduction of in cylinder residuals was predicted. At low speeds, increase residuals were identified due to the change in engine breathing. Provided stable combustion can be maintained, this has the effect of reducing the throttling required and further increasing engine efficiency. At mid speed and load, the effect would be reverse and reduced residuals will require more throttling and increased pumping work. At high speeds, the residual content increases slightly, however, it is anticipated that with VVA strategies, the residual content across the entire map could be improved. 


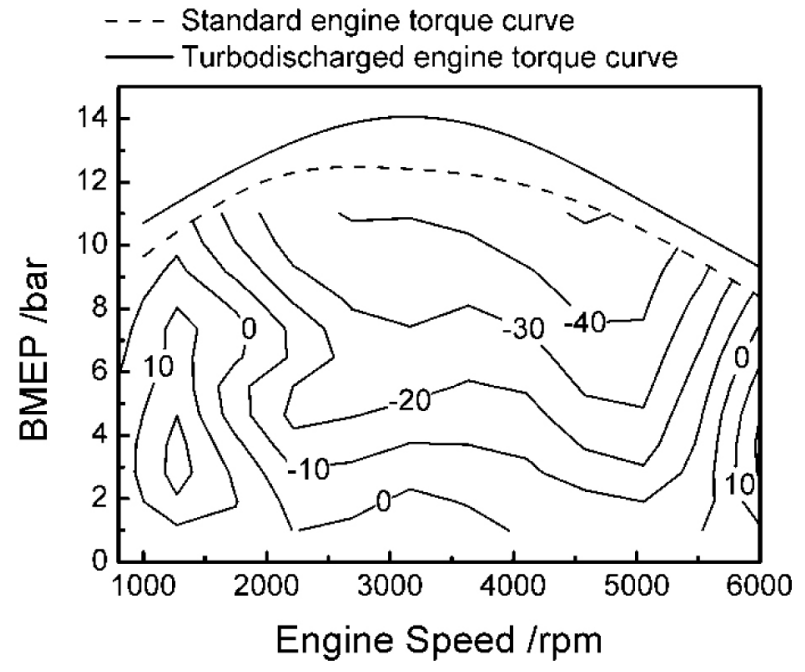

Figure 15. Effect of Turbo-Discharging on trapped residual fraction (\% increase)

\section{$\underline{\text { Sensitivity Analysis }}$}

The results so far presented a single valve timing applied across the entire engine operating range. The following discussion investigates how sensitive the system behavior is to LP exhaust valve timing, HP exhaust valve timing, the amount of heat removed (via heat exchanger size) and the turbomachine efficiency. To represent different regions of the map the following cases are presented:

1. $2000 \mathrm{rpm}$, full load

2. $5000 \mathrm{rpm}$, full load

3. $2000 \mathrm{rpm}, 4$ bar BMEP

4. $4000 \mathrm{rpm}, 6$ bar BMEP

$2000 \mathrm{rpm}$, full load

Figure 16a shows the sensitivity of the exhaust port pressure to the variables previously described. Notably, the system is remarkably insensitive to these variables. The most significant variable is the turbomachine efficiency which, by varying between 30 and $42 \%$, results in a 0.2 bar variation in exhaust system pressure. The low pressure valve timing has almost no effect. The high pressure valve timing is slightly more sensitive since with high cylinder pressures, early valve opening results in higher pressures and temperatures at the start of blowdown and therefore more energy available to reduce the exhaust system pressure. Heat exchanger size has negligible effect indicating that the heat exchanger is oversized for this operating condition.

The torque increase resulting from Turbo-Discharging, shown in Figure 16b, is sensitive to turbomachine efficiency. The effect of high pressure valve opening is very small despite the effect on exhaust system pressure as earlier valve opening also reduces the expansion work from the engine.
Later low pressure exhaust valve timings increase valve overlap with the intake system and therefore allow improved scavenging and increased torque.

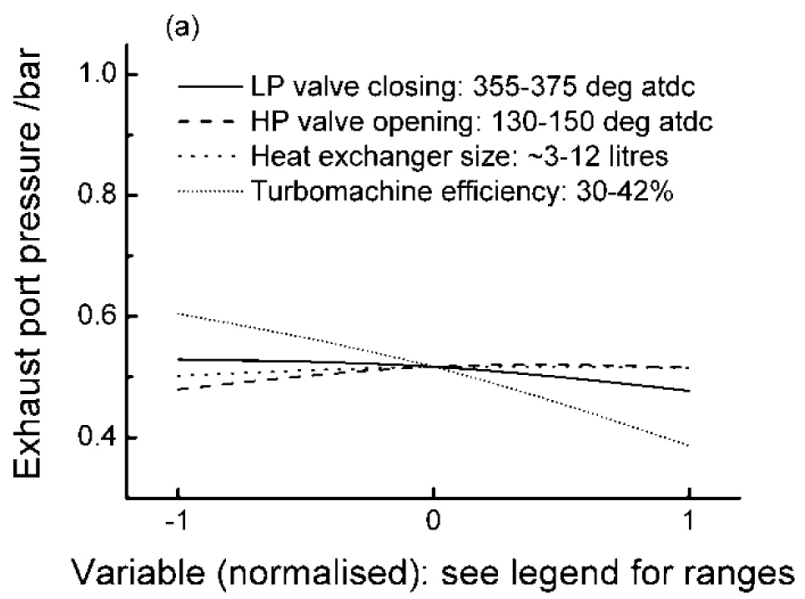

(b)

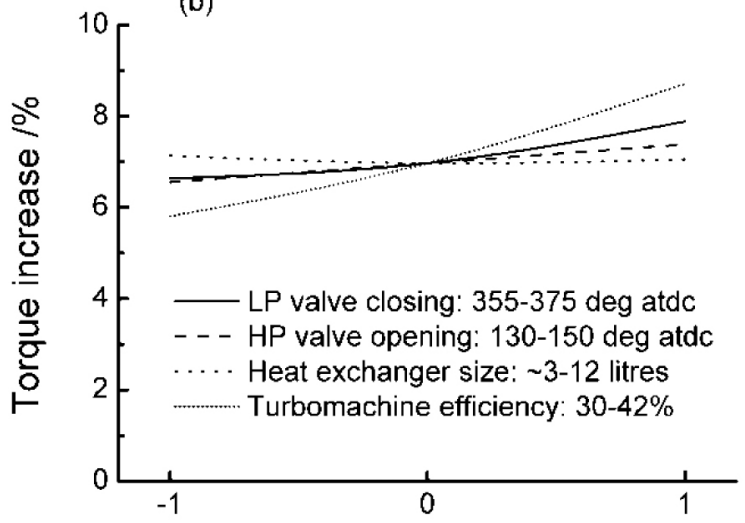

Variable (normalised): see legend for ranges

Figure 16. Sensitivity of (a) exhaust port pressure and (b) torque increase, to valve timing, heat rejection and turbomachine efficiency at 2000 rpm full load

$5000 \mathrm{rpm}$ full load

At higher engine speeds $(5000 \mathrm{rpm})$ the comparable sensitivity plots are shown in Figure 17. The importance of turbomachine efficiency is still apparent. The effects of valve timing were comparable to that in Figure 16. The effect of the heat exchanger is small, but more significant than at lower speeds. As with the previous case, the system is remarkably insensitive to the range of variables studied. The trade-off between heat exchanger size and benefit is most significant at high powers. If the importance is placed at lower engine power conditions, the heat exchanger size can be significantly reduced. 


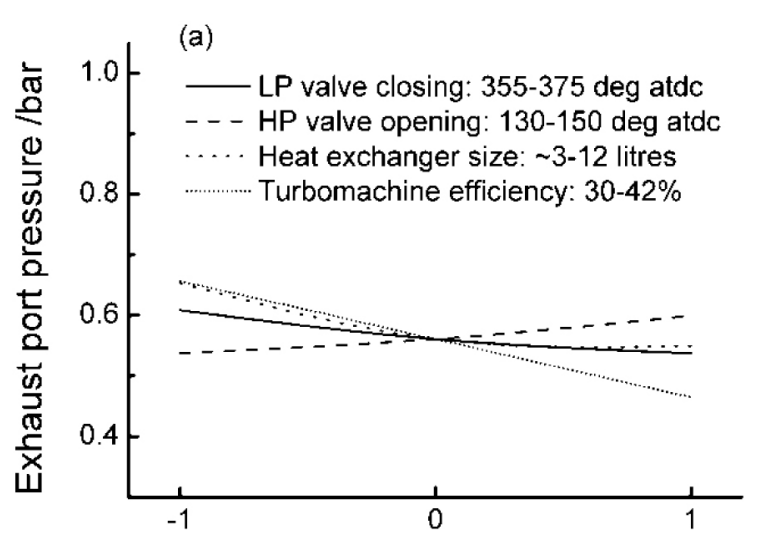

Variable (normalised): see legend for ranges

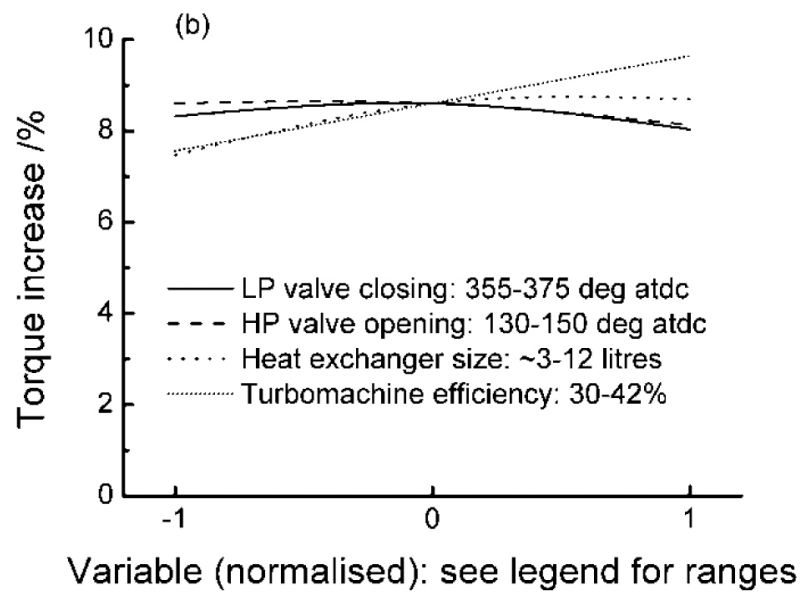

Figure 17. Sensitivity of (a) exhaust port pressure and (b) torque increase, to valve timing, heat rejection and turbomachine efficiency at 5000 rpm full load

Part load

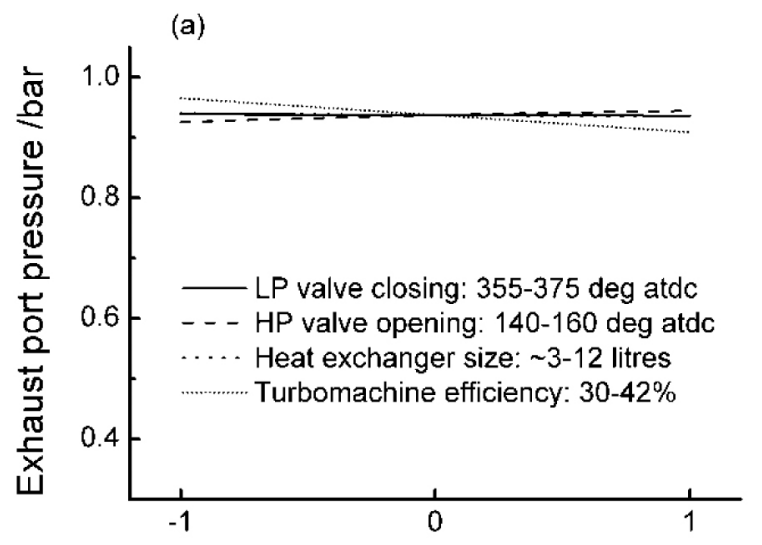

Variable (normalised): see legend for ranges

Figure 18. Sensitivity of exhaust port pressure to valve timing, heat rejection and turbomachine efficiency at (a) 2000 rpm 4 bar BMEP and (b) 4000 rpm 6 bar BMEP

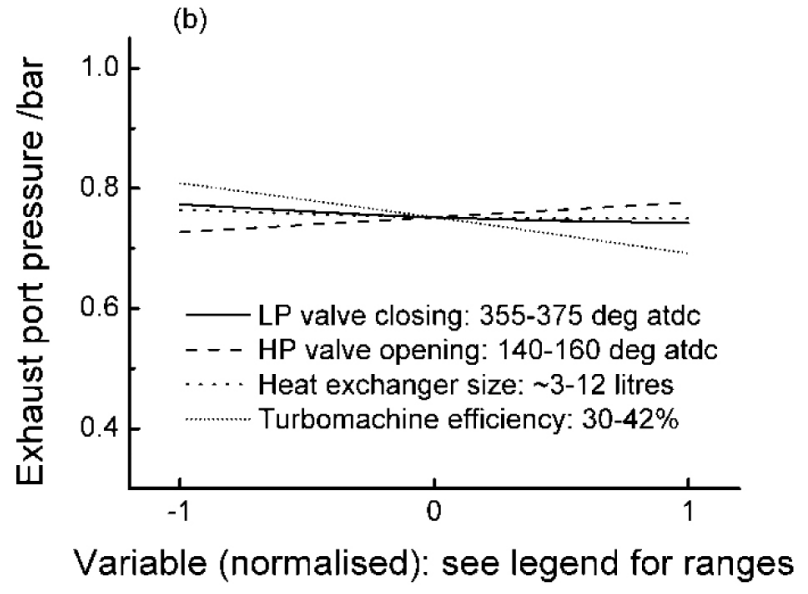

Figure 18 (cont.). Sensitivity of exhaust port pressure to valve timing, heat rejection and turbomachine efficiency at (a) 2000 rpm 4 bar BMEP and (b) 4000 rpm 6 bar BMEP

Figures $18 \mathrm{a}$ and $18 \mathrm{~b}$ show the exhaust system pressure at $2000 \mathrm{rpm} 4$ bar BMEP and $4000 \mathrm{rpm} 6$ bar BMEP respectively. The trends support the discussion for the full load cases where the importance of heat exchanger size only starts to become apparent at higher engine powers.

Summary of Sensitivity Study

In summary, Turbo-Discharging is not sensitive to exhaust valve timing ( $+/-10$ deg crank angle) or heat exchanger size (between 3 and 12 litres). This indicates that manufacturing variations and tolerances do not need to be tightened to achieve a positive result. The turbomachine efficiency has the most significant effect. To achieve fast transient response with conventional turbochargers there are many design features, such as scalloping of the turbine blades and small turbine size that have resulted in $\sim 20 \%$ reduction in turbomachine efficiency[ $[9]$. It is important to understand the effect of the transient response of this system on driver perceptions as the peak engine power is less dependent on Turbo-Discharging than it would be with a conventional turbocharger system. This may allow significantly more efficient turbomachines to be used. A thorough study of transient response is beyond the scope of the work presented here.

The packaging in automotive engine bays is a significant challenge and the heat exchanger size should be minimized. Varying heat exchanger size between 3 and 12 litres was shown to not significantly affect the engine performance. The effect of heat exchanger size was investigated further. The exhaust system pressure at $5000 \mathrm{rpm}$, full load is shown in Figure 19 for heat exchanger sizes approaching 0 litres. Significant reduction in exhaust system pressure was seen at very small heat exchanger sizes. In addition, if priority is assigned to lower engine power operating conditions, the 
thermal demand on the heat exchanger will be significantly reduced.

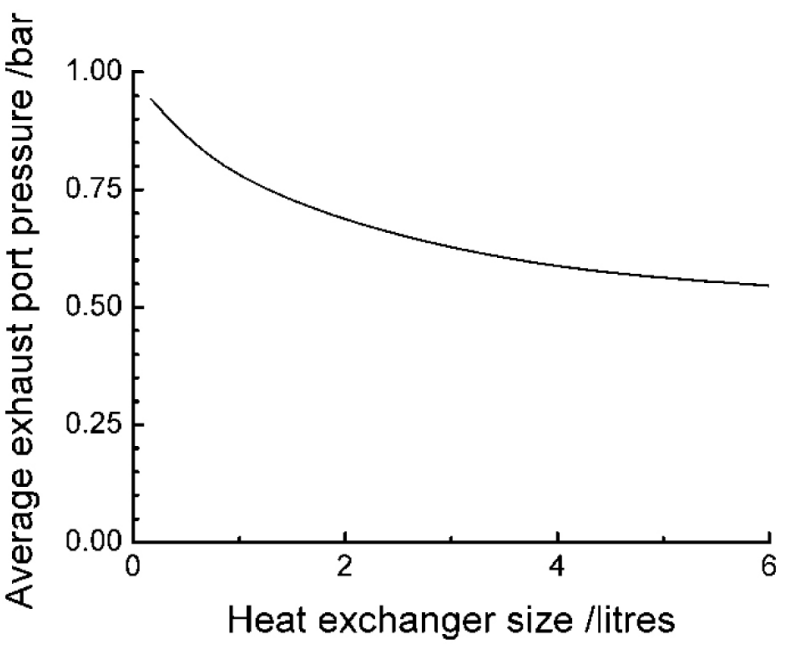

Figure 19. Effect of heat exchanger size on exhaust port pressure at $5000 \mathrm{rpm}$, full load

\section{TURBO-DISCHARGING TURBOCHARGED ENGINES}

Future fuel economy and $\mathrm{CO}_{2}$ emission targets are likely to require downsizing of engines. This would be achieved by turbocharging which introduces a further level of complexity to the Turbo-Discharging system. Initial studies are focused on naturally aspirated engines to understand the fundamentals of the Turbo-Discharging system, however, it was important to explore the impact of increasing engine power density, particularly on engine breathing capability. A schematic of the exhaust arrangement for the Turbo-Discharged turbocharged engine has already been shown in Figure 2 . Since the post TC turbine pressure is lower, the pressure ratio across the TC turbine is higher and more work can be done for the same upstream exhaust system pressure. The net result is, to achieve the same engine boost levels, a lower back pressure will be applied to the engine. The gas will have further expanded and be at a lower temperature on turbine entry offering additional benefits for VGT turbocharger durability. Calculation of the exhaust port pressures needed to achieve a specific turbine energy recovery are shown in Figure 20 for the conventional engine and a TurboDischarged engine to compare the effect of TurboDischarging (with a pressure ratio of 2 across the compressor) on exhaust system back pressure (as seen by the engine). Higher specific turbine energies correspond to higher boost levels and, therefore, engine load. The reduction in back pressure increases with specific turbine energy recovery at a slower rate than engine power output would. Therefore, at higher boost conditions, the fuel economy benefit will be smaller than at lower boost conditions.

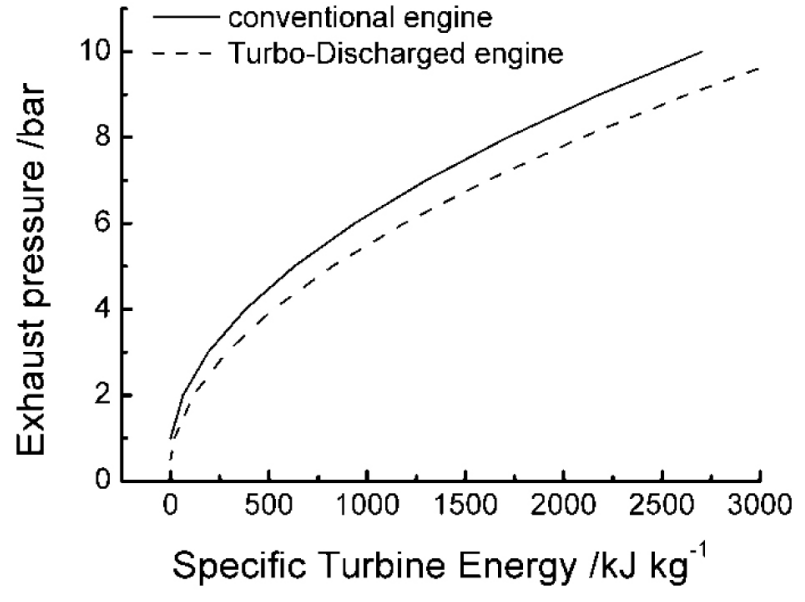
Figure 20. Effect of Turbo-Discharging on exhaust port back pressure as a function of turbocharger turbine energy demand

Figures 21 and 22 show the predicted fuel economy benefit from the 0-D simulations described previously, applied to turbocharged diesel and gasoline engine architectures respectively. The benefit is a maximum at mid loads, reducing at light loads due to the reduced blowdown intensity. At higher loads, the engine torque increases more than the possible improvements to BMEP meaning that the overall fuel economy benefit reduces. Although the highest benefit was predicted at high engine speeds, breathing limitations will limit the fuel economy benefit at these conditions. For the case of the gasoline engine, assuming a VGT is used to minimize the engine back pressure and fuel consumption, the maximum benefit is observed at approximately the same BMEP as the naturally aspirated engines. As the BMEP increases further, the improvements to PMEP are smaller in comparison to the increases in BMEP and as such, the relative benefit reduces. Due to modeling assumptions, benefits at higher power conditions are expected to be an overestimate due to flow restrictions across valves.

To understand the potential of Turbo-Discharging on higher power density engines, the 1-D naturally aspirated engine model was modified to represent a pressure charged engine (e.g. supercharged) to investigate the breathing limits on the valve timings chosen. Combustion and in-cylinder pressure limits were not considered so that the focus was on the breathing limits related to the valves and manifolds. The results are shown in Figure 23. As the power density increased the peak engine torque at $5000 \mathrm{rpm}$ approached that of the same engine model without Turbo-Discharging (i.e. conventional valve timings and exhaust system). At approximately $130 \mathrm{~kW}$ litre $^{-1}$ the power output at $5000 \mathrm{rpm}$ was the same between both engines. At $170 \mathrm{~kW}$ litre $^{-1}$ the power output of the Turbo-Discharged engine had reduced to $\sim 0.5 \%$ less than the equivalent engine with conventional valving and exhaust systems. Despite this reduction in torque 
at high speeds, the majority of the torque curve below 5000 rpm was higher with the Turbo-Discharging system.

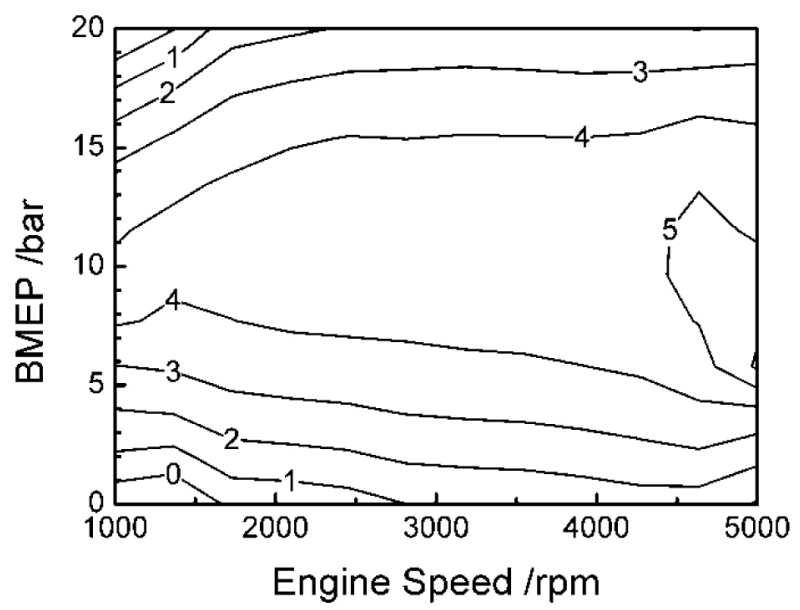

Figure 21. Predicted Fuel economy improvements (\%) for a turbocharged diesel engine

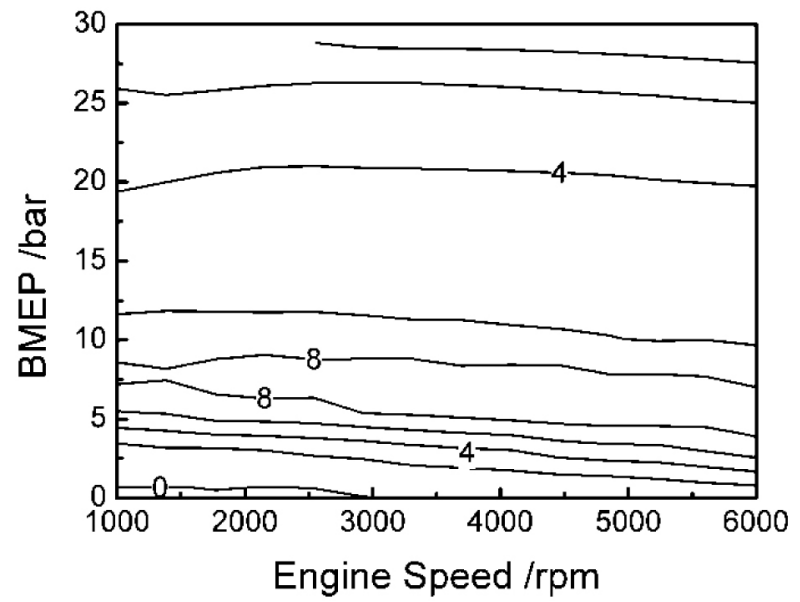

Figure 22. Predicted fuel economy improvements (\%) for a turbocharged gasoline engine

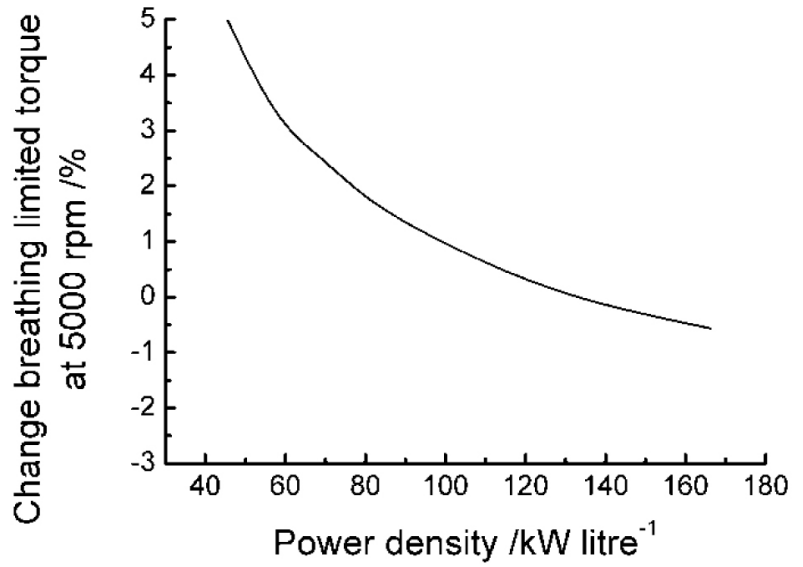

Figure 23. Effect of intake pressure boosting on breathing limited torque benefit of Turbo-Discharging at $5000 \mathrm{rpm}$, full load

Figure 24 shows the fresh air flow into the engine as a function of speed at $\sim 170 \mathrm{~kW}$ litre $^{-1}$ engine power density. Across the entire engine speed range the engine airflow is increased. This would normally be reflected in an increase of engine peak power, however, the reduced exhaust valve events under such high power densities result in higher back pressures during the exhaust stroke. Figure 25 shows the incylinder pressure during the exhaust stroke. Through most of the stroke the in-cylinder pressures are significantly higher and contribute up to 1 bar to the PMEP. However, towards the end of the exhaust event, the in-cylinder pressures are significantly lower. With no valve overlap this in itself would significantly reduce hot residuals. With valve overlap, the lower exhaust pressures promote flow from the intake through to the exhaust, further reducing in-cylinder trapped residuals.

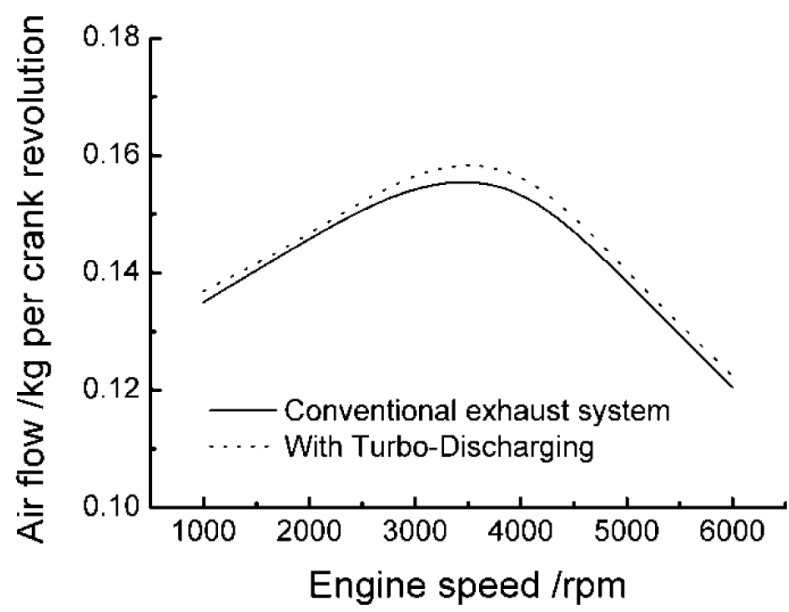

Figure 24. Engine full load fresh air flow as a function of engine speed at $\sim 170 \mathrm{~kW}^{\text {litre }}{ }^{-1}$ engine power density, full load 


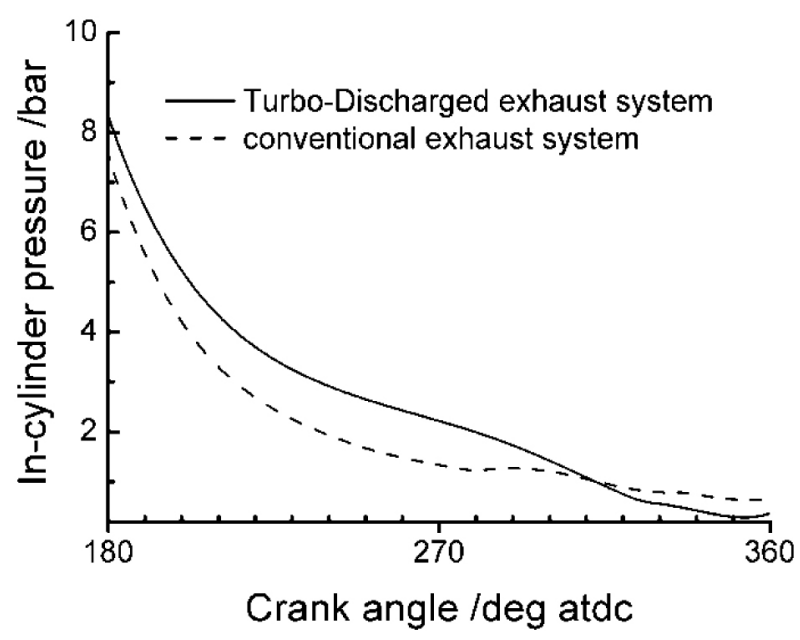

Figure 25. Comparison of in cylinder pressure during the exhaust stroke between conventional and TurboDischarged exhaust systems

On closer inspection of the exhaust system pressures it was apparent that the pulse flow from the engine can be translated through the Turbo-Discharging turbine. Such translation of the pulse through the Turbo-Discharging turbine will have advantages for maintaining the transient response and low speed torque of a turbocharging system. The amount of pulse translation through the Turbo-Discharging turbine is a function of exhaust system geometry and can be adapted to match the desired engine air system characteristics.

The aim of the research reported here was to explore the characteristics and potential behavior of Turbo-Discharging system. These scoping studies on modified naturally aspirated engine models have indicated that the potential benefits are tangible on downsized and turbocharged engines. Indeed, the effect on in-cylinder residuals may allow more significant benefits on downsized gasoline engines. Further simulated and experimental study of application of Turbo-Discharging to boosted engines is an important area for our ongoing future research.

\section{DISCUSSION}

Figure 26 shows a computer generated representation of a geometry similar to that which was modeled. Each cylinder has two isolated ports. The high pressure ports converge close to the turbine inlet and the low pressure ports converge close to the turbine outlet. The entire exhaust flows through a heat exchanger and into the compressor inlet before being exhausted. The system lends itself well to compact pipe-work and a relatively small packaging volume.

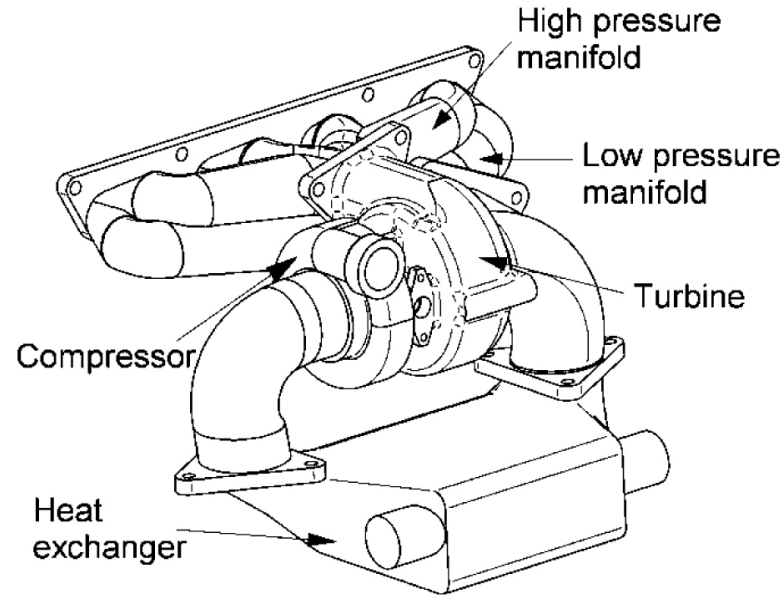

Figure 26. CAD image showing the main components of the Turbo-Discharging system

These simulations did not consider the integration of aftertreatment systems with Turbo-Discharging. The lower gas pressure in the exhaust system combined with the energy removed by the turbine will result in lower exhaust gas temperatures when compared to a conventional engine at moderate mean effective pressures which may affect operational temperatures and fuel enrichment requirements to maintain catalyst and turbine durability. During idle warmup in throttled engines there is no positive blowdown event which means that the turbo-machine will not be active and the exhaust conditions will be comparable to the warmup of a conventional engine. A wastegate (or equivalent) feature in the turbo-machine would allow control of the level of TurboDischarging to balance thermal requirements and breathing requirements of the engine. The effect of Turbo-Discharging on exhaust gas recirculation (EGR) systems is also important. Appropriate pressure ratios between exhaust and intake are required to maintain high enough EGR flow rates. The peak pulsing pressures should be comparable to conventional engine architectures, however, the average pressure is lower and the EGR and Turbo-Discharging systems will interact strongly. A significant challenge for the proposed system will be the effect of surface fouling of, in particular, the compressor and diffuser. This may be of particular importance when the gas has been significantly cooled. The axial thrust loading of the Turbo-Discharging turbomachine will be typically higher than on a conventional turbocharger due to the significantly lower compressor outlet pressures which should be considered with thrust bearing design. The required heat exchanger size, and therefore packaging demand is strongly dependent on the required performance at peak power. If the focus is on part load, low to mid engine speeds, the requirements for the heat exchanger become significantly less stringent. In the longer term, it is likely that no additional heat exchanger will be required as the heat will be removed by thermal heat recovery systems as part of the wider effort for fuel economy improvement. The 
quantification of the interactions described here are the focus of current experimental research efforts and will be reported in future publications.

\section{CONCLUSIONS}

This paper has, for the first time, introduced the novel TurboDischarging system which recovers energy from the blowdown pulse of IC engines and uses it to depressurize the engine exhaust system. Turbo-Discharging can be applied to any engine topology where there is a blowdown event. The paper has presented the results of modeling studies investigating the characteristics and behavior of the TurboDischarging system and explored its application to naturally aspirated and, to a lesser extent, boosted engine architectures. This will aid future experimental programs and has led to the following conclusions:

1. Turbo-Discharging can reduce or even reverse pumping losses from an internal combustion engine by reducing the exhaust manifold pressure. Exhaust pressures of $<0.5$ bar absolute were predicted for the naturally aspirated engine. This increased engine torque and improved fuel economy over a significant fraction of the engine map.

2. Fuel economy improvements of $\sim 5 \%$ were predicted when compared to a naturally aspirated engine of the same power.

3. At all engine conditions investigated, the naturally aspirated engine Turbo-Discharging system performance is relatively insensitive to exhaust valve timing and heat exchanger size. Turbo-machine efficiency has a more important effect.

4. The lower exhaust pressure will translate through a turbocharging system turbine to give lower pumping losses on a turbocharged engine.

5. Trapped residual content is reduced significantly for both naturally aspirated engines ( $>40 \%$ reduction) and is anticipated for highly boosted engines due to lower in cylinder pressures around EVC and an intake to exhaust pressure ratio that encourages scavenging. This could offer significant secondary benefits to combustion by extending the knock limit.

6. Preliminary investigations of boosted engine breathing indicated that breathing limited engine torque improvements will occur below power densities of $\sim 140 \mathrm{~kW}$ litre $^{-1}$. However, at all power densities included, the trapped (hot) residual fraction was significantly reduced giving scope for increased boost or compression ratio by extending the knock limit.

The preliminary modeling results are encouraging. The technological challenges such as packaging, EGR system integration and exhaust gas aftertreatment integration are important and will form part of future experimental study of the performance of a Turbo-Discharging system on-engine.

\section{REFERENCES}

1. Shahed, S. and Bauer, K., "Parametric Studies of the Impact of Turbocharging on Gasoline Engine Downsizing," SAE Int. J. Engines 2(1):1347-1358, 2009, doi: 10.4271/2009-01-1472.

2. Flierl, R., Paulov, M., Knecht, A., and Hannibal, W., "Investigations with a Mechanically Fully Variable Valve Train on a 2.01 Turbo Charged Four Cylinder Engine," SAE Technical Paper 2008-01-1352, 2008, doi: 10.4271/2008-01-1352.

3. Mori, M., Yamagami, T., Oda, N., Hattori, M. et al., "Current Possibilities of Thermoelectric Technology Relative to Fuel Economy," SAE Technical Paper 2009-01-0170, 2009, doi: $\underline{10.4271 / 2009-01-0170 .}$.

4. Ringler, J., Seifert, M., Guyotot, V., and Hübner, W., "Rankine Cycle for Waste Heat Recovery of IC Engines," SAE Int. J. Engines 2(1):67-76, 2009, doi:

10.4271/2009-01-0174.

5. Lyu, M., Doo, B., and Ku, Y., "A Study of Vehicle Fuel Economy Improvement Potential by Optimization of the Cooling and Ancillary Systems of a Heavy Duty Engine," SAE Technical Paper 2007-01-1772, 2007, doi: 10.4271/2007-01-1772.

6. Improving fuel efficiency with laser surface textured piston rings. Etsion, I. and Sher, E.. Tribology International Vol 42 pp 542-547, 2009.

7. Möller, C., Johansson, P., Grandin, B., and Lindström, F., "Divided Exhaust Period - A Gas Exchange System for Turbocharged SI Engines," SAE Technical Paper 2005-01-1150, 2005, doi:10.4271/2005-01-1150.

8. Improvements in or relating to internal combustion engines. Society Rateau. British patent no. 12,227/22, 1924

9. Fundamentals of Turbocharging. Baines, N.C.. Concepts NREC, Vermont, USA, 2005

\section{CONTACT INFORMATION}

Dr. Andy Williams

Wolfson School of Mechanical and Manufacturing

Engineering

Loughborough University

Leicestershire LE11 3TU

UK

A.M.Williams@lboro.ac.uk

Tel: +44 1509227651

\section{ACKNOWLEDGEMENTS}

The authors would like to acknowledge the support the Royal Academy of Engineering and that of the Engineering and Physical Sciences Research Council (EPSRC) and Technology Strategy Board (TSB) as part of the Low Carbon 
Vehicles Integrated Delivery Programme (Grant EP/ H050353/1) for supporting this research.

\section{DEFINITIONS/ABBREVIATIONS}

0-D

Zero-dimensional

1-D

One-dimensional

\section{BMEP}

Brake mean effective pressure

CAD

Computer aided design

$\mathrm{CO}_{2}$

Carbon dioxide

EVC

Exhaust valve closing

HP

High pressure

IC

Internal combustion

LP

Low pressure

NA

Naturally aspirated

\section{PMEP}

Pumping mean effective pressure
TC

Turbocharged

VGT

Variable geometry turbine

VVA

Variable valve actuation 